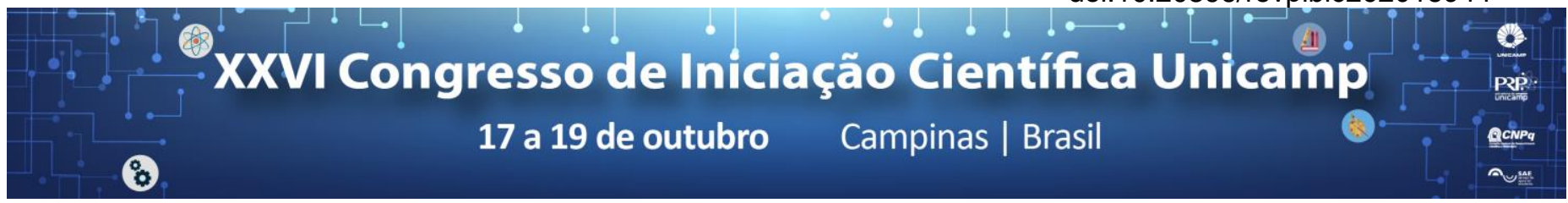

\title{
Pesquisa dos benefícios de um programa de resiliência climática ao produtor
}

\section{Luke Zhi Wei Zheng*, Alexandre Gori Maia}

\section{Resumo}

Foram feitas manipulções de códigos por meio do programa RStudio para a extração de dados meteorológicos. Esses extração foi feita a partir do INMET (Instituto Nacional de Meteorologia), que apresenta 265 estações metereológicas no território brasileiro.

\section{Palavras-chave:}

tecnologia agrícolo, agricultura familiar, semiárido

\section{Introdução}

Este projeto de iniciação científica enquadra-se em uma pesquisa mais ampla aplicada na região semiárida baiana, e que tem como objetivos centrais: avaliação dos impactos econômicos do sistema produtivo mais proposto pelo projeto Adapta Sertão, identificando as soluções tecnológicas e o arranjo produtivo integrado que mostrem o possível caminho da resiliência climática do produtor familiar do semiárido brasileiro.

Foram feitas elaboradas funções no programa estatístico RStudio para extração dos dados meteorológicos. Esses dados posteriormente foram utilizados para interpolar valores das estações em objeto grid pelo método IDW (Inverso da Distância Ponderado).

\section{Resultados e Discussão}

A partir da base de dados do INMET (Instituto Nacional de Meteorologia), o BDMEP (Banco de Dados Meteorológicos de Ensino e Pesquisa), foram extraídas as seguintes variáveis de 265 estações:

- Precipitação (mm)

- Temperatura máxima $\left({ }^{\circ} \mathrm{C}\right)$

- Temperatura mínima (ํㅜ)

- Insolação (horas)

- Evaporação do Piche (mm)

- Temperatura Compensada Média $\left({ }^{\circ} \mathrm{C}\right)$

- Umidade Relativa Média (\%)

- Velocidade Vento Média (mps)

A partir dessas variáveis foram selecionadas três variáveis para aplicar a interpolação nas estações de cada município brasileiro.

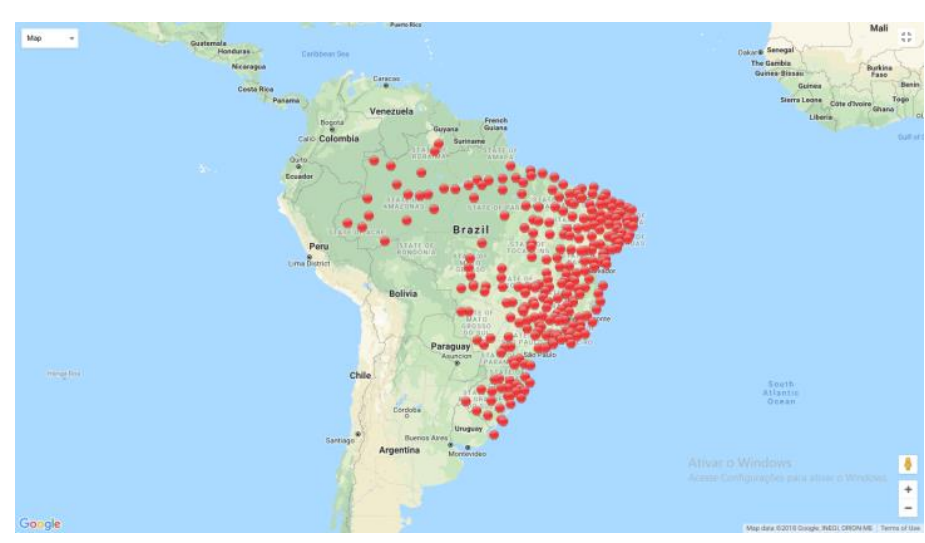

Figura 1. Distribuição das estações do BDMEP

\section{Conclusões}

O método de interpolação IDW (Inverso da Distância ponderada), permite predizer valores em estações sem observação. Essa predição é baseada nos valores amostrados à sua volta, sendo que as mais próximas terão um peso maior, do que as mais distantes. Em outras palavras, conforme a distância aumenta, o peso da observação diminui.

Como a maior parte das estações observadas está localizada na região litorânea do país (Figura 1), a interpolação próxima a esses locais provavelmente será muito precisa. Enquanto os valores preditos para locais mais distantes dessa área, podem ter menos precisão.

\section{Agradecimentos}

Serviço de Apoio ao Estudante (SAE)

Fundação CAPES

Instituto de Economia da Unicamp (IE) 